\title{
LA PRIMERA TRANSFORMACIÓN DE MÉXICO: ANÁLISIS DE LOS ARGUMENTOS FILOSÓFICOS PRE-INDEPENDENTISTAS
}

\section{THE FIRST TRANSFORMATION OF MEXICO: ANALYSIS OF THE PRE-INDEPENDENCE PHILOSOPHICAL ARGUMENTS}

\author{
Cecilia Guadalupe Sabido Sánchez Juárez (Ed.) \\ Universidad Autónoma de San Luis Potosí, \\ Facultad de Ciencias Sociales y
}

Humanidades, 2020, pp. 292.

Hace dos años se constituyó un grupo de investigación humanística encargado de realizar un proyecto a largo plazo que estudiara los argumentos filosóficos de las llamadas «cuatro transformaciones de México», para entender si lo son y en qué consistieron. Recordemos las tres primeras transformaciones de México: independencia, reforma y revolución. Este libro, cuya edición estuvo a cargo de la doctora Cecilia Sabido Sánchez Juárez es, en sus palabras, «un estudio en busca de los principios filosóficos que subyacen, posibilitan y actúan en los procesos de cambio en torno a la independencia de México».

En este libro se compilan nueve artículos de autores que exploran distintos temas y problemáticas alrededor de las ideas filosóficas, sociopolíticas, educativas y culturales que influyeron en el movimiento de independencia mexicano. En cada capítulo han contribuido investigadores expertos en los temas que tratan. Las diferentes tradiciones que alimentaron intelectualmente y formaron el movimiento insurgente, están presentes en los artículos: desde los problemas teológicos escolásticos novohispanos sobre la libertad humana y el origen de la legitimidad del gobierno, hasta las consideraciones ilustradas sobre la naturaleza racional del hombre. De igual modo, concurren en estas páginas, personajes académicos señeros que forjaron las ideas y los valores insurgentes a lo largo de poco menos de un siglo, desde mediados del siglo XVIII -o incluso antes- hasta la primera mitad del siglo XIX: sor Juana Inés de la Cruz, Juan José de Eguiara y Eguren, Francisco Xavier Clavijero, Gorriño y Arduengo, Melchor de Talamantes, Francisco Primo de Verdad, entre muchos otros. 
A veces puede parecer un reto comprender las causas y vertientes del movimiento insurgente mexicano. Mucho más si nos atenemos a una historia oficial, en la que héroes y heroínas privan, como estatuas de piedra, sobre los hombres y las mujeres que formaron la verdadera historia, con sus decisiones libres y cotidianas. En este sentido, la historia oficial puede ser un peligro para la comprensión del desarrollo de las ideas que alimentaron procesos como el movimiento insurgente.

Es inadecuado juzgar la insurgencia mexicana desde los criterios contemporáneos, más bien debe analizarse desde una identidad que apenas estaba siendo formada en el diálogo de muchas influencias: filosofía escolástica católica, liberalismo clásico británico, ilustración francesa e hispánica. El encuentro fue variado y no monolítico, ni con la finalidad predestinada de formar una identidad mexicana inmediata.

Al libro lo conforman dos partes. La primera (páginas 23-158), dedicada a los antecedentes filosóficos novohispanos que permitieron sustentar las bases de la identidad nacional, desde los ámbitos cultural y social. La segunda parte (páginas 159-296) analiza los argumentos filosóficos independentistas en diferentes tradiciones y momentos, durante la transformación que consolidó al nuevo estado mexicano. Cada artículo ofrece una aproximación más crítica a los hitos históricos y culturales, y procura replantear una comprensión clarificadora de las diversas tradiciones y argumentos que justificaron la consolidación del movimiento de independencia.

\section{«Tradiciones filosóficas en el concepto de libertad de sor Juana Inés de la Cruz»}

El primer artículo, escrito por María del Rosario Avilés Sánchez, reflexiona sobre el tratamiento que propuso sor Juana al problema de la libertad humana, desde dos fuentes principales: el pensamiento de san Agustín y el del jesuita Francisco Suárez. Como monja criolla novohispana, recibió una educación centrada en los clásicos grecolatinos y cristianos, sin omitir a los recientes clásicos de la escolástica española frente a la reforma protestante.

En su comprensión del problema de la libertad, sor Juana sigue el linaje de san Agustín, santo Tomás, Martín Lutero y Francisco Suárez. La ruptura que supuso la reforma protestante implicó una revisión de los argumentos que Lutero propuso sobre la agencia humana en el «De servo arbitrio». La propuesta luterana fue revisada y refutada por el Concilio de Trento, cuyos lineamientos recogió Suárez al decir que «si el hombre es libre, es moralmente responsable por sus acciones» (p.35). La respuesta católica se sintetizó en la oposición de dos maneras de pensar en la «Disputa De auxiliis».

Por una parte estaban los jesuitas, liderados por Luis de Molina y sustentados en el pensamiento suareciano, que enfatizaban la libertad humana individual. Por otra, los dominicos, guiados por Domingo Báñez, subrayaban la omnipotencia de Dios sobre los individuos. La disputa fue conocida por Antonio Núñez de Miranda, confesor de sor Juana. Incluso llegó a escribir un «Tractatus de Scientia Dei y Tractatus de Scienzia Media et de Auxiliis», sintetizando las ideas suarecianas y molinistas (p. 46). De este modo, sor Juana estuvo en contacto con estas nociones gracias a su confesor, y las manifestó en textos defensores de la libertad como la «Carta atenagórica» o la «Respuesta a Sor Filotea de la Cruz». Asimismo, el artículo muestra los orígenes de la idea de libertad a las que el linaje del pensamiento de sor Juana pertenece. 


\title{
«En defensa de un proyecto culturalmente diferenciado.
}

\section{Los Anteloquia, de Juan José de Eguiara y Eguren»}

El segundo artículo, de Mónica del Carmen Meza Mejía, gira en torno a los veinte Anteloquia o Prólogos a la «Bibliotheca mexicana» del sacerdote y académico criollo de origen vasco, Juan José de Eguiara y Eguren (1696-1763), como un proyecto cultural y académico que implica ya una consideración de la mexicanidad -distinguida de la hispanidad-, desde la primera mitad del siglo XVIII. Como criollo y académico universitario novohispano, Eguiara se da a la tarea de divulgar la identidad de la mexicanidad en sus diversas manifestaciones: culturales, literarias, naturales, etnográficas, para destacarla de la mera identidad hispánica:

\begin{abstract}
Este erudito, consciente de estar creando un nuevo significado para el término «mexicano», como él mismo lo explica en el prólogo XX, busca dar a conocer el mundo americano a través de la Bibliotheca mexicana: lo fértil de su suelo; las bondades de su clima; lo fecundo de su espiritualidad y la prodigalidad de su cultura, orgullosa de su pasado prehispánico y de su herencia peninsular (p. 58).
\end{abstract}

En este sentido, los Anteloquia o Prólogos de la «Bibliotheca mexicana» pretenden ser, por una parte, un reconocimiento de los orígenes y la cultura compartida con Occidente, como el pensamiento grecolatino y el cristianismo; por otra, un punto de separación de lo compartido, para mostrar lo propiamente mexicano frente a la alteridad de las culturas mencionadas.

Ello aclara la función de la identidad cultural que quiere reafirmar el letrado novohispano: la diferenciación, para definir quién se es. Es así como, mediante esta dualidad de la pertenencia y de la exclusión, se construye la identidad cultural que quiere expresar Eguiara en los Prólogos, que se escriben para mostrar ante el mundo (el hispano principalmente) a un grupo social y a un territorio, con el que comparte unos rasgos distintivos, espirituales, materiales y afectivos propios. Englobando de este modo, las artes y las letras, los modos de vida, las tradiciones, los valores y las creencias, entre otros aspectos culturales (p. 59).

Los Anteloquia o Prólogos, bases filosóficas que sirven de preámbulo a la Bibliotheca mexicana, permiten la comprensión de esta obra enciclopédica como un discurso de recuperación de la identidad mexicana frente a los prejuicios europeos. Es así que:

Los Anteloquia como ejercicio sistematizado de refutación discursiva, legitiman la función del criollo letrado, que con autoridad decodifica la condición americana, redefiniendo asertivamente, el valor de lo prehispánico, del proceso de aculturación que se sucede a partir de la Conquista y de los sujetos originarios y sobrevenidos del continente americano, como parte de una nueva realidad mexicana (p. 73).

\section{«La palabra, misterio del hombre y manifestación del espíritu»}

Ana Isabel Pliego Ramos considera, en este trabajo, el aporte de Francisco Xavier Clavijero (1731-1787), sobre la naturaleza lingüística del ser humano y sus repercusiones en el ámbito de la ética y las relaciones sociales, sin dejar de considerar la capacidad de expresión de los matices de las lenguas indígenas mexicanas sobre estos temas, y que Clavijero retoma en sus análisis. En palabras de su autora: 


\begin{abstract}
En este texto analizo la contribución de Francisco Javier Clavijero a la antropología filosófica, en lo concerniente a la realización de la libertad humana. Me centro en las aportaciones de Clavijero sobre el lenguaje que encontramos en Historia Antigua de México y en sus Disertaciones, pues estas manifiestan un conocimiento profundo del hombre y una racionalidad plena no fincada en lo concreto (p. 78).
\end{abstract}

Este escrito comprende dos divisiones principales. La primera establece el contexto histórico en el que Clavijero se mueve, así como las intenciones lingüísticas y hermenéuticas que dirigen su trabajo, Historia antigua de México, como un proyecto ilustrado y de proyección universalista; la segunda muestra el empleo de la palabra en los matices de las lenguas indígenas y que Clavijero retoma como manifestación de una cosmovisión: expresión del ser, del deber ser, la libertad, la racionalidad humana. En este sentido, el artículo consigue un acercamiento a la filosofía del lenguaje y a la hermenéutica del pensamiento indígena mesoamericano que Clavijero analiza desde la propia naturaleza de las lenguas, culturas y cosmovisiones indígenas.

\title{
«Las dos Guadalupes y la independencia»
}

Jorge Medina Delgadillo es autor de este artículo que menciona el breve y poco conocido opúsculo de Francisco Xavier Clavijero intitulado Breve informe sobre la prodigiosa y renombrada imagen de Nuestra Señora de Guadalupe de México, en el cual el jesuita veracruzano presenta, a Europa, la identidad mexicana a través de la figura de la Virgen de Guadalupe del Tepeyac. Desde su formalidad histórica, Clavijero hila datos, fechas, documentos e hipótesis para mostrar por qué la identidad mexicana es ininteligible sin la Virgen de Guadalupe.

Los orígenes de la devoción guadalupana se remontan a la España medieval, al Real monasterio de Guadalupe en Extremadura, convertido en un centro de peregrinaciones e identidad, al final de la guerra de Reconquista. La Virgen extremeña consolidó la identidad cultural y nacional hispánica del aquel tiempo. Por otra parte, la Virgen mexicana, expresa el encuentro hispano y mesoamericano, como síntesis de ambas culturas. El autor no discute la cuestión aparicionista o antiaparicionista en este artículo. Esta identidad guadalupana novohispana criolla se consolidó durante el siglo XVII, popularizándose por todo el territorio virreinal en el siglo XVIII, gracias a la acción formativa de los jesuitas, como Clavijero.

El mismo historiador llevó esta devoción a Italia durante su exilio y escribió el texto en cuestión para presentar lo mexicano en Europa, aprovechando las similitudes de las dos imágenes marianas guadalupanas, pero enfatizando la novedad identitaria de la Guadalupe mexicana. Medina Delgadillo apunta:

\footnotetext{
Mientras que la Guadalupe de Extremadura unificaba a la cristiandad española, conectando con los visigodos, sus verdaderos antepasados, a pesar de los ocho siglos de dominación mora, otro tanto ocurre con la mexicana. Ambas morenas: la de México es indígena en sus rasgos y evoca la mirada de una princesa náhuatl cuyo atavío, que cumple con la visión apocalíptica de tantas imágenes inmaculadas, está además ornamentada -en la imagen y en el relato del Nican mopohua- de la flor y el canto (xochitl in cuicatl), pues toda ella es un poema, de acuerdo a la cosmovisión náhuatl. La extremeña busca un origen, el visigodo, ante la reciente expulsión de la impiedad musulmana; la mexicana busca también un origen ante la reciente conversión de la impiedad mexica (p. 113).
} 


\section{«¿Se puede hablar de una Ilustración novohispana?»}

Luis Bazet y Paola Coronado son coautores de este trabajo que examina el problema de la existencia de una Ilustración novohispana, frente a la clara existencia de Ilustraciones como la francesa, británica, o alemana. El punto de partida para resolver el problema -si el movimiento ilustrado novohispano es diferente al europeo- es que el término Ilustración se puede decir de muchas maneras. Por eso los autores cuestionan:

La cuestión a la que nos enfrentamos comienza con una consideración sobre la naturaleza de la influencia ilustrada. ¿Esta influencia fue meramente externa o en algún punto se vio internalizada? En otras palabras: ¿los pensadores mexicanos preindependentistas meramente recibieron ideas de Europa y de las colonias norteamericanas o, por otra parte, asimilaron dichas ideas y las asumieron y recrearon desde el propio contexto y circunstancia? ¿ $\mathrm{O}$ es de hecho el caso que las obras de estos pensadores se inspiran, en todo caso, en otras tradiciones? (p. 126).

Se exploran, pues, las formas en que sí puede afirmarse una Ilustración novohispana en su propio modo, y en qué sentido sus propuestas fueron puntos de apoyo para la posterior causa insurgente mexicana.

\section{«Invenciones doctrinales en torno a la llamada "Guerra de Independencia"»}

El sexto artículo, de la segunda parte del libro (Argumentos filosóficos en la transición), pertenece a Manuel Andreu Gálvez. El escrito subraya el error de llamar a la insurgencia mexicana como «Guerra de independencia», ya que este es un término forjado en el siglo XIX, y que no se ajusta al contexto histórico en que sucedió la lucha. En palabras del autor:

El presente estudio guarda el propósito de incorporar, de manera breve, las cuestiones doctrinales en torno a la mal llamada «Guerra de la Independencia»-concepto utilizado según el sentido y discurso decimonónico, que no es compatible con los hechos históricos sucedidos-, puesto que la carga mítica que conlleva el término fue necesaria en el enfoque que la historiografía liberal le dio al período independiente para la construcción de uno de los hechos oficiales más importantes de nuestro tiempo, como es el de la nación política contemporánea (p. 161).

De este modo, Manuel Andreu Gálvez explora temas políticos y filosóficos que dieron origen a la insurgencia mexicana, dentro de su propio contexto, y aclara el error anacrónico de considerar el movimiento como «Guerra de Independencia».

\section{«La formación de la patria y los ideales ilustrados en San Luis Potosí. Educación, sociedad y ley en Manuel María de Gorriño y Arduengo»}

Cecilia Sabido Sánchez Juárez ahonda en las ideas políticas del potosino Manuel María de Gorriño y Arduengo (1767-1831), autor poco conocido fuera de su ámbito regional. Este sacerdote novohispano y mexicano, participó en la formación de la identidad nacional desde la oratoria, la educación en colegios y también desde la política, pues fue diputado por San Luis Potosí, en el Congreso constituyente de 1824:

Para evidenciar el proceso de transformación del país, desde la Nueva España al México independiente, el caso de Manuel María Gorriño y Arduengo resulta del todo pertinente. No sólo 
nos brinda la perspectiva de las provincias, sino que despliega su participación y reflexión de las ideas filosóficas que subyacen a la Independencia, a lo largo de toda su vida (p. 181).

El escrito revisa los orígenes de los argumentos políticos de Gorriño, que van desde el modernismo hasta el liberalismo, y retoman las ideas de personajes como Benito Díaz de Gamarra. Además, se quiere

[...] mostrar cómo, a través de la obra de Gorriño, es posible descubrir la influencia de una tradición ilustrada plural, ecléctica, que retoma y critica a los autores modernos desde el eclecticismo novohispano del XVIII, sin dejar de lado la tradición humanista que discurrió en la Nueva España desde su fundación (p. 182).

\section{«Criollismo preindependentista o Ilustración francesa}

\section{a la luz de la idea de pueblo en los discursos de 1808-1811»}

Virgina Aspe Armella profundiza sobre las diversas nociones de «pueblo», que legitimaron el discurso novohispano e insurgente, entre los años 1784-1811. El artículo reflexiona sobre diversos autores como Miguel Hidalgo, el jesuita peruano Juan Pablo Viscardo y Guzmán, el jesuita mexicano Pedro Márquez o el alemán Alexander von Humboldt.

Asimismo, estudia la idea de «pueblo» en el contexto novohispano frente a su contraparte europea de la época. Esta oposición se une a la que confrontó, de diversos modos, la recepción de la filosofía moderna y el desarrollo tradicional de la escolástica. Por ejemplo, Hidalgo es favorable a no dejar la escolástica, pero sí a abrirse a los nuevos temas y modos filosóficos de la modernidad. El estudio se divide en cuestiones de contexto, de análisis de historia cultural del Barroco criollo, de análisis de los escritos de Miguel Hidalgo y Costilla, y de filósofos políticos de discurso preindependentista, del análisis de la evolución del término «pueblo» en los textos y, por último, de las argumentaciones filosóficas preindependentistas en la primera transformación y su balance (cfr. p. 223).

Estas consideraciones metodológicas y de inclusión de contexto cultural, me permiten dividir mi escrito en: a) cuestiones de contexto, b) análisis de historia cultural del Barroco criollo, c) análisis de los escritos de Miguel Hidalgo y Costilla y otros filósofos políticos de discurso preindependentista, d) análisis de la evolución del término «pueblo» en los textos y, por último, e) argumentaciones filosóficas preindependentistas en la primera transformación y su balance (p. 223).

\section{«Las interpretaciones sobre la Independencia de México a la luz de la $4^{\text {a }}$ Transformación. ¿Dos siglos de confusiones?»}

Este trabajo de Luis Aarón Patiño Palafox, busca aclarar los modos en que en la época contemporánea -y sobre todo el presente sexenio-, ha interpretado el proceso de Independencia de México como primera transformación. ¿Ha sido esta una interpretación recta a partir de la comprensión del propio contexto histórico y social? ¿O ha pasado a tener un significado diferente, según los intereses políticos presentes?

El autor aclara qué significa «transformación» en el actual ambiente político, y si la Independencia, la Reforma y la Revolución lo fueron realmente, o si la ilación de estas tres -en el 
mismo ideario político- es una ideologización actual (p. 282). El autor procede a sintetizar las críticas que Virginia Aspe y Guillermo Hurtado han realizado sobre las ideas principales del actual gobierno de México, que pretende hacer suyos los sucesos históricos mencionados dentro de una narrativa de legitimación propia. Al respecto de esto, Patiño Palafox apunta:

Para entender nuestro nacimiento como nación, debemos ver a nuestra tradición criolla, hispanoamericana e iberoamericana. Cualquier intento de simplificación está condenado a repetir premisas medianamente ciertas y a negar la rica tradición de pensamiento político que dio la Nueva España, que quizás sea más sutil para explicar la larga duración y repercusiones actuales de ese contexto (p. 289).

Gabriel González Nares

Universidad Panamericana, Ciudad de México 